\title{
Predictors of Ips confusus Outbreaks During a Record Drought in Southwestern USA: Implications for Monitoring and Management
}

\author{
Maria J. Santos • Thomas G. Whitham
}

Received: 26 January 2009/ Accepted: 21 November 2009/Published online: 23 December 2009

(c) The Author(s) 2009. This article is published with open access at Springerlink.com

\begin{abstract}
In many ecosystems the effects of disturbance can be cryptic and disturbance may vary in subtle spatiotemporal ways. For instance, we know that bark beetle outbreaks are more frequent in temperate forests during droughts; however, we have little idea about why they occur in some locations and not others. Understanding biotic and abiotic factors promoting bark beetle outbreaks can be critical to predicting and responding to pest outbreaks. Here we address the environmental factors which are associated with Ips confusus outbreaks during the 2002 widespread drought within the distribution range of pinyon pine woodlands in Arizona. We used univariate statistics to test if whether tree characteristics, other herbivores, stand properties, soil type, wind, and topography were associated with I. confusus outbreak, and logistic regression to create a predictive model for the outbreaks. We found that I. confusus attacks occur in low elevation stands on steeper slopes, where favorable winds for I. confusus dispersion occur. I. confusus select larger trees, in high density stands with understory shrubs that exhibit phenotypic traits characteristic of resistance to stem-boring moths. The model
\end{abstract}

\section{J. Santos}

Center for Environmental Sciences and Education, Northern Arizona University, PO Box 5694, Flagstaff, AZ 86001-5694, USA

\section{J. Santos ( $\square)$}

Department of Land, Air and Water Resources, University of California, One Shields Avenue, Davis, CA 95616-8585, USA e-mail: mjsantos@ucdavis.edu

T. G. Whitham

Department of Biological Sciences and Merriam-Powell Center for Environmental Research, Northern Arizona University, PO Box 5640, Flagstaff, AZ 86011, USA was highly accurate, and explained $95 \%$ of the variability in occurrence (98\% of the absences and $95 \%$ of the presences). Accurate prediction of the impacts of disturbance allow us to anticipate, minimize or mitigate for and eventually counteract its effects, especially those affecting diversity and ecosystem function. Identification of outbreak risk areas can guide regional and national management towards the reduction of infestation risk and enhancing conservation of pinyon-juniper woodlands.

Keywords Bark beetle outbreaks - Ips confusus . Geographical modeling $\cdot$ Pinus edulis $\cdot$ Record drought

\section{Introduction}

Disturbances such as drought are major drivers of landscape pattern and dynamics, often affecting ecosystem processes and functions by changing plant composition (Gitlin and others 2006; Breshears and others 2005). Despite the observable landscape effects of drought, often indirect effects are overlooked, as is the case of subsequent bark beetle outbreaks (Powers and others 1999). Bark beetles (Coleoptera: Curculionidae) are among the most destructive agents of conifer forests worldwide, such as loblolly pine (Pinus taeda) (Fredericksen and others 1995), red pine (Pinus resinosa) (Erbilgin and Raffa 2002), ponderosa pine (Pinus ponderosa) (Logan and others 1998; Sánchez-Martínez and Wagner 2002), Douglas fir (Pseudotsuga menziesii) (Negron 1998; Powers and others 1999), and Norway spruce (Picea abies) (Weslien and Schroeder 1999). The legacy of bark beetle outbreaks in the landscape, especially when causing exacerbated die-off of their hosts, may persist over long periods of time. However, to anticipate where those landscape patterns may occur, a 
quantitative description of the mechanisms of bark beetle host selection and their effects at the landscape scale is still needed.

In North America, forest management practices subsequent to Euro-American settlement have altered forest structure and species composition towards even-aged monospecific stands, which made them highly susceptible to bark beetle outbreaks (Trapp and Croteau 2001). These conditions were aggravated in naturally semi-arid and water stressed environments such as pinyon-juniper woodlands (Allen and Breshears 1998; Ogle and others 2000; TrotterIII and others 2002). Pinyon (Pinus spp.)-juniper (Juniperus spp.) woodlands are widely distributed in Mexico and western U.S.A. In Arizona, pinyon pine ( $P$. edulis) occurs from intermediate $(1,200 \mathrm{~m})$ to high $(2,200 \mathrm{~m})$ elevations, mainly in soils with high mean annual soil temperature and low to intermediate annual precipitation. In 1996, a major bark beetle, Ips confusus, infestation occurred in these woodlands associated with a major drought event, and it was estimated that local stands of pinyon pine trees suffered up to $70 \%$ mortality (Mueller and others 2005). In 2002, the most severe drought on record occurred in this region. Importantly, it was found that the same sites that suffered high tree mortality in 1996 also suffered the highest mortality in 2002 (Mueller and others 2005), suggesting that subsequent droughts reinforced tree mortality patterns established during earlier droughts. Associated with an increase in drought severity across these years was an estimated 20-fold increase in I. confusus damage (USDA 2003), which attack recently killed, weakened or dying trees (Campbell and others 2008).

In general, bark beetles outbreaks rely on the combination of multiple factors including bark beetle population parameters (e.g., fecundity, reproductive rate), tree and stand characteristics (e.g., type, age and abundance of host tree), abiotic factors (e.g., strong winds, avalanches, landslides), and human-caused disturbance (Gilbert and Grégoire 2003). However, individual species and site specific characteristics may vary and the combination of which factors trigger outbreaks in any given region is still unknown, and few studies have addressed these factors at the landscape scale. Although some effort was put forward to understand host-tree characteristics (Byers 1996; Reeve 1997; Logan and others 1998; Negron 1998; Gilbert and Grégoire 2003; Negron and Popp 2004), it was never extended to identify the characteristics predicting outbreaks in pinyon pine in a real landscape setting (Powers and others 1999).

We aimed to develop a model for predicting the spatial occurrence of $I$. confusus outbreaks in pinyon pine in the southwestern U.S.A. To understand I. confusus outbreaks in pinyon pine woodlands we examined putative factors that are likely to affect bark beetle habitat selection. We addressed five hypotheses: (1) Taller, larger and mature pinyon pines provide greater food availability than smaller pinyon pines, despite potentially having better defenses against herbivory, and thus are preferred by I. confusus; (2) proximity to $I$. confusus infested pinyon pine stands increases probability of future infestation; (3) pinyon pines on south-facing steep slopes at lower elevations are more water-stressed and therefore more susceptible to I. confusus attack; (4) dominant winds (NE and SW) promote I. confusus directional dispersal, and; (5) reduced soil water content decreases pinyon pine resistance, making trees vulnerable to I. confusus attack. Assessing these hypotheses is important for determining key habitat variables during outbreaks, and predictive modeling of future I. confusus outbreaks. The outcome of this study also helps us understand how I. confusus can act as cryptic keystone species (Brown and others 2001) that affect the abundance and distributions of the approximately 1000 species of organisms associated with pinyon pine forests (Whitham and others 2003).

\section{Study Area}

In November 2002 four study sites were selected in the $P$. edulis distribution range in Arizona. The overall study area is located in northern Arizona and extends from the Grand Canyon to the Mogollon Rim (Fig. 1). Sites were selected to represent the variability of soil types (following Hendricks 1985) within the pinyon pine distribution range (Table 1): (1) Thermic arid soil site-located at the Grand

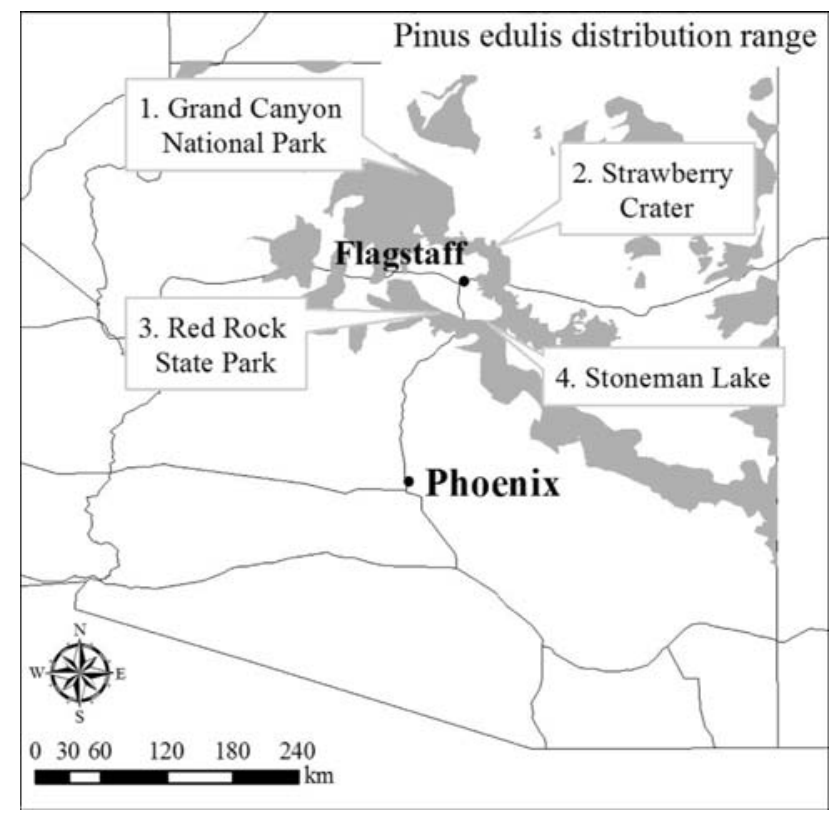

Fig. 1 Distribution range of Pinus edulis in Arizona (grey) and location of study sites (1) Grand Canyon National Park; (2) Strawberry Crater; (3) Red Rock State Park; and (4) Stoneman Lake 
Canyon National Park, $\sim 140 \mathrm{~km}$ NW of Flagstaff; (2) mesic subhumid soil site-located in Strawberry Crater, $\sim 32 \mathrm{~km}$ NE of Flagstaff; (3) frigid subhumid soil site at Stoneman Lake (Coconino National Forest), $\sim 24 \mathrm{~km} \mathrm{E} \mathrm{of}$ Sedona; and (4) mesic semiarid soil site at the Red Rock State Park, $\sim 8 \mathrm{~km}$ south of Sedona. Despite the stratification by soil type, data were pooled and soil type used as a candidate variable (See Predictor Variables section).

\section{Methods}

At each sample site, three random transects (approximately $2.5 \mathrm{~km}$ each) were established, incorporating $\mathrm{N}$ - and S-facing aspects, steep and flat areas, and high and low elevations. In the first two transects 80 trees were sampled and data used for model development, and in the third transect 20 trees were sampled and data used for accuracy assessment of the developed model. Tree location was recorded by Geographic Positioning System (Garmin Inc. accurate to $5 \mathrm{~m}$ ). Each sampled tree was spaced between 30 and $45 \mathrm{~m}$ to avoid that multiple trees would fall into the same raster cell (see Predictor Variables section). Furthermore, field data were screened to avoid this problem and any problematic cell was excluded from the analysis.

\section{Predictor Variables}

Biotic and abiotic factors were recorded for 400 trees in the four main soil types in the pinyon pine distributional range in 2002 (Table 2). I. confusus outbreaks usually start in areas with live trees (Reid and Robb 1999) are stressed by drought, disease, old age, and the presence of snags and fallen trees. Since our goal was to estimate the stand conditions that enhanced I. confusus outbreak and because the study was conducted a posteriori of beetle infestation, we used beetle presence-absence as the response variable. We believe that selecting presence as an indicator of beetle density does not greatly affect the results of this study because it has been shown that at low beetle densities, I. confusus are only found in stressed trees, whereas at high bark beetle densities healthy and unhealthy trees were killed (Wallin and Raffa 2002); the latter corresponds to our case. We quantified I. confusus presence and tree vigor by sampling the following traits for each tree: I. confusus presence (estimated by detecting the presence of larvae or adult beetles on main trunk and larger branches), tree age (visual assessment of tree height into mature and sapling categories), canopy cover (canopy drip-line, i.e., circular area covered by each individual tree canopy), height, and perimeter at breast height (tree perimeter was converted to $\mathrm{DBH})$. We tested if the presence of sub-canopy vegetation would also affect $I$. confusus outbreaks, due to the reported 
Table 2 Variables used in the tree and landscape level models for I. confusus infestation in Arizona

\begin{tabular}{|c|c|c|c|c|c|}
\hline Variable & Model & Source & Unit & Type & Categorization \\
\hline I. confusus presence & Tree and landscape & Field data & NA & Categorical & Presence/absence \\
\hline Tree age & Tree & Field data & NA & Categorical & Sapling/mature \\
\hline Tree canopy & Tree & Field data & NA & Categorical & Open/closed \\
\hline Tree height & Tree & Field data & $\mathrm{cm}$ & Continuous & NA \\
\hline Perimeter of the trunk & Tree & Field data & $\mathrm{cm}$ & Continuous & NA \\
\hline Tree DBH & Tree & Estimated from field data & $\mathrm{cm}$ & Continuous & NA \\
\hline Food availability & Tree & Estimated from field data & $\mathrm{cm}^{3}$ & Continuous & NA \\
\hline Scale presence & Tree & Field data & NA & Categorical & Presence/absence \\
\hline Moth resistant phenotype & Tree & Field data & NA & Categorical & Resistant/susceptible \\
\hline Sub-canopy presence & Tree & Field data & NA & Categorical & Presence/absence \\
\hline Distance to nearest tree & Tree & Field data & $\mathrm{cm}$ & Continuous & NA \\
\hline Age of nearest tree & Tree & Field data & NA & Categorical & Sapling/mature \\
\hline I. confusus in near. Tree & Tree & Field data & NA & Categorical & Presence/absence \\
\hline Scale in nearest tree & Tree & Field data & NA & Categorical & Presence/absence \\
\hline Moth resistant phenotype in nearest tree & Tree & Field data & NA & Categorical & Presence/absence \\
\hline Soil type & Landscape & USDA coverage & NA & Categorical & MH/MS/FH/TA \\
\hline Aspect & Landscape & Extracted from DEM & $30 \times 30 \mathrm{~m}$ & Continuous & NA \\
\hline Slope & Landscape & Extracted from DEM & $30 \times 30 \mathrm{~m}$ & Continuous & NA \\
\hline Elevation & Landscape & Extracted from DEM & $30 \times 30 \mathrm{~m}$ & Continuous & NA \\
\hline Wind & Landscape & Extracted from Aspect & $30 \times 30 \mathrm{~m}$ & Continuous & NA \\
\hline
\end{tabular}

$M H$ mesic subhumid soil, $M S$ mesic semiarid soil, $F H$ frigid subhumid soil, $T A$ thermic arid soil, $N A$ non applicable

association of bark beetles with sub-canopy structure, fallen trees and vegetation (Reid and Robb 1999).

To address the effect of tree density and measure the probability that the closest infested neighbors affecting uninfested trees, we measured the distance from an infested tree to the nearest tree (measured from trunk to trunk), and I. confusus presence in the nearest tree. We also quantified the presence of two other common herbivores along each transect, which might affect the distribution of I. confusus by interference competition. The pinyon pine needle scale (Matsucoccus acalyptus, Homoptera: Margarodidae), attacks juvenile pinyons and is easily detected by its presence on the needles and/or an open tree architecture caused by massive needle loss (Cobb and Whitham 1993; Gehring and others 1997). We also assessed the presence of the stem-boring moth (Dioryctria albovittella, Coleoptera: Pyralidae), which kills the terminal shoots of mature trees causing them to develop a shrub-like appearance rather than a normal, upright conifer architecture (Whitham and Mopper 1985; Brown and others 2001). Because these two herbivores could affect the distribution and host colonization of I. confusus, we quantified their presence or absence for the scale infestations, and moth resistant and susceptible phenotypes, in both the I. confusus infested trees and their nearest neighbor tree (Table 2). I. confusus is a phloem feeder, and phloem thickness would constitute an accurate measure of the food available to them. Because phloem thickness requires labor intensive and destructive sampling we used the volume of the cylinder around the trunk as an index of food availability-estimated as trunk cross-sectional area multiplied by tree height. There is an allometric relationship between tree volume and phloem thickness (Jackson and others 1999).

Landscape scale variables were determined a posteriori using a Geographic Information System (GIS) of the study area, in a grid $(30 \times 30 \mathrm{~m})$ corresponding to the available digital elevation model (DEM) for the study area (Fig. 1). UTM coordinates of all trees were incorporated into the GIS and the following landscape-level variables were derived for each grid cell containing a sampled tree: soil type, aspect, elevation, slope and dominant wind (Table 2). NE $\left(30^{\circ}-60^{\circ}\right)$ and $\mathrm{SW}\left(210^{\circ}-240^{\circ}\right)$ aspects were selected from the aspect layer to create a dominant wind layer (Klink 1999). NE and SW aspects were attributed a value of 1 , all other aspect values were attributed a value of 0 .

\section{Data Analyses and Modeling}

All variables were tested for normality and transformations were performed when needed. We used Pearson correlation coefficients to determine the variables associated with I. confusus presence. Those variables with significant correlation with $I$. confusus presence were tested for 
differences in sites with and without $I$. confusus using oneway analysis of variance. We used Bonferroni correction to correct alpha values for the multiple comparisons (Zar 1999).

Univariate statistical results were used to screen candidate variables for model development. The use of excessive variables in model development may cause model overfitting (i.e., two or more different variables in the model account for the same variability in the results, which may result in spurious results). To avoid model over-fitting candidate variables were tested for autocorrelation. We determined the Pearson correlation coefficient between each pair of candidate variables. When two candidate variables were correlated $(r>0.5)$, only that variable with higher correlation with $I$. confusus presence was selected for further analysis. We also tested for variable spatial autocorrelation using Moran's (1950) index, and when this autocorrelation was significant we included an autologistic term into the predictive model.

Selected variables were incorporated into a multiple logistic regression to generate a combined predictive model. This analysis has been developed for use with wildlife (amphibians, birds and mammals), but few studies have applied these methods to predict pest outbreaks (Negron 1998; Negron and Popp 2004). The model was allowed for 100 iterations where candidate variables were tested to enter the model. At each iteration, the variable with the $P$-value of the Wald statistic exceeding 0.10 was removed from the model. At any iteration candidate variables were allowed to enter the model if the candidate variable had $P<0.05$ and those variables already in the model had $P<0.10$ (Hosmer and Lemeshow 2000).

Model performance was assessed using internal (from the data used to develop the model) and external (from an additional data set not used in the model development) validation. Internal validation was obtained by an adjusted $R^{2}$ value and a classification table (Burnham and Anderson 1998; Guisan and Zimmermann 2000). Probabilities of I. confusus presence at each tree in the validation data set were predicted using the constructed model and then compared with the observed presence/absences. The classification table and percent error rates (percent correctly predicted presences and absences, percent incorrectly predicted presences-commission error-and absencesomission error) are the product of these comparisons.
External validation used an accuracy assessment data set (from the 20 trees sampled in the third transect at each sample site), estimated the probability of I. confusus presence at each point and compared it with the observed values using a classification table and percent error rates (Burnham and Anderson 1998; Guisan and Zimmermann 2000). We assumed that predicted probabilities higher than $60 \%$ corresponded to presence of $I$. confusus. In addition, we used the receiver operating characteristic (ROC) curves to test the rate of true positive fraction (sensitivity) and the true negative fraction (specificity), when compared to a random distribution of the predicted presences/absences (Hanley and McNeil 1982). ROC calculates the area under the curve (AUC) which represents the probability that a randomly chosen observation will be correctly classified. AUC values vary between 0.5 and 0.99 and the closer the value is to 0.99 , the better the performance of the predictive model (Hanley and McNeil 1982). Statistical analysis was performed using JMP 4.0, SPSS 13, ArcView 3.2 and ArcGIS 8.0 (ESRI, CA), with a significance level of 0.05 .

\section{Results}

\section{Rates of Ips confusus Attack}

Ips confusus were detected at all four sampled sites (Table 1). Of the 320 sampled trees used for model development, I. confusus were found in $37.5 \%(n=120)$ of the trees. Attack rates were higher for trees in Strawberry Crater, Red Rock State Park and Grand Canyon National Park (Table 1).

Most of the tree and landscape variables showed highly significant differences between attacked and non-attacked trees (ANOVA $P$-value $<0.01$ ), with the exception of tree canopy, aspect and Mesic Semiarid soil (Table 3).

Modeling I. confusus Responses to Trees and Landscape

We used the individual traits of the 320 trees analyzed, to develop a predictive habitat model of the distribution of I. confusus. The logistic regression model derived for I. confusus response to trees and landscape resulted in the following equation:

$$
P(\text { Ips confusus })=\frac{1}{1+e^{-263.108+2.665 \log _{10} F+3.466 I_{t}-2.665 \text { moth }+0.125 \text { elev }+0.253 \text { slope }-2.347 \text { wind }}}
$$


Where $F$ is the estimate of the food availability (volume of the cylinder around the trunk), $I_{\mathrm{t}}$ indicates whether or not the nearest tree was infested, moth is the presence of moth resistant phenotype, and elev, slope and wind are elevation, slope and wind, respectively. Infestation of the nearest tree and food availability significantly increased the probability that a tree would be infested with I. confusus. On the other hand, moth resistant phenotype and unfavorable wind had a significant negative effect on the presence of I. confusus infestation (Table 4). Elevation and slope also had significant, but with small positive effects on the probability of finding $I$. confusus, as their regression coefficients demonstrate.

Our model has good overall predictive ability. Internal accuracy assessment (with the data used to train the model) showed that this model correctly classified $98 \%$ of the absences and $95 \%$ of the presences. Overall model predictability was $96.9 \%$. External accuracy assessment (with an additional data set) performed with equally high correct classification rates (Table 4). As described in the methods,
AUC was significantly greater than random (area $=0.998$, $P \ll 0.001)$, showing a high predictive power of the model.

\section{Discussion}

During a record drought in northern Arizona, I. confusus outbreaks occurred in steep lowland areas with favorable winds, in larger trees, and with stem-boring moth resistant phenotypes that had infested trees nearby. Following, we discuss the extent our findings corroborate or refute the effect of biotic and abiotic factors on the likelihood of I. confusus outbreaks in northern Arizona.

\section{Predictors of $I$. confusus Outbreaks}

Stand condition affects bark beetle swarming dates (Amezaga and Rodríguez 1998), population size (Hanula and Franzreb 1998), reproductive success (Reid and Robb 1999), and colonization (Erbilgin and Raffa 2002).

Table 3 Pearson correlation coefficients, ANOVA, descriptive statistics (Mean and 95\% confidence intervals) and percentage of each class of tree and landscape variables and $I$. confusus presence in pinyon pine

\begin{tabular}{|c|c|c|c|c|}
\hline Variable & $r$ & ANOVA & $\begin{array}{l}\text { I. confusus presence } \\
\text { Mean; }(95 \% \text { CI) }\end{array}$ & $\begin{array}{l}\text { I. confusus absent } \\
\text { Mean; }(95 \% \text { CI) }\end{array}$ \\
\hline Easting ( $x$ coordinate) & $-0.144 *$ & $F=6.69 * *$ & 438824; [434554,443094] & 443872; [441188,446555] \\
\hline Northing ( $y$ coordinate) & $0.188 * *$ & $F=11.61 * *$ & 3907229; [3895241,3919216] & 3885465; [3877382,3893548] \\
\hline Tree age & $0.174 *$ & $F=9.94^{* *}$ & $\begin{array}{l}\text { Sapling }=20.8 \% \\
\text { Mature }=79.2 \%\end{array}$ & $\begin{array}{l}\text { Sapling }=37.5 \% \\
\text { Mature }=62.5 \%\end{array}$ \\
\hline Tree canopy & 0.021 & - & - & - \\
\hline Tree height $(\mathrm{cm})$ & $0.228 * *$ & $F=17.46^{* *}$ & $405.1 ;[377.8,432.3]$ & $332.3 ;[309.2,355.4]$ \\
\hline Perimeter of the trunk $(\mathrm{cm})$ & $0.243 * *$ & $F=19.87 * *$ & $64.3 ;[57.5,71.1]$ & $45.4 ;[40.3,50.4]$ \\
\hline Tree DBH $(\mathrm{cm})$ & $0.279 * *$ & $F=26.84 * *$ & $30 ;[26.8,33.2]$ & $21.2 ;[18.8,23.5]$ \\
\hline Food availability $\left(\mathrm{cm}^{3}\right)$ & $0.278 * *$ & $F=26.56^{* *}$ & 484050; [349959,618141] & 250276; [184357,316195] \\
\hline Scale & $-0.163 * *$ & $F=8.72 * *$ & $\begin{array}{l}\mathrm{NA}=81 \% \\
\text { Susceptible }=1.3 \% ; \text { Resistant }=17.7 \%\end{array}$ & $\begin{array}{l}\mathrm{NA}=60.3 \% \\
\text { Susceptible }=7.1 \% \text {; Resistant }=32.6 \%\end{array}$ \\
\hline Moth & $0.179 * *$ & $F=10.50 * *$ & $\begin{array}{l}\mathrm{NA}=20 \% \\
\text { Susceptible }=12.7 \% \\
\quad \text { Resistant }=68.4 \%\end{array}$ & $\begin{array}{l}\mathrm{NA}=39 \% \\
\text { Susceptible }=5.7 \% ; \text { Resistant }=55.3 \%\end{array}$ \\
\hline Sub-canopy presence & $0.123 *$ & $F=4.86^{* *}$ & Absent $=46.7 \% ;$ Present $=53.3 \%$ & Absent $=59.8 \% ;$ Present $=40.2 \%$ \\
\hline Distance to nearest tree $(\mathrm{m})$ & $-0.138 *$ & $F=4.26^{* *}$ & $2.85 ;[2.12,3.59]$ & $4.67 ;[3.69,5.66]$ \\
\hline I. confusus in nearest tree & $0.504 * *$ & $F=108.00 * *$ & Absent $=34.2 \% ;$ Present $=65.8 \%$ & Absent $=81.6 \% ;$ Present $=18.4 \%$ \\
\hline Mesic semiarid & 0.075 & - & & \\
\hline Mesic subhumid & $0.134 *$ & $F=5.83^{*}$ & & \\
\hline Frigid subhumid & $-0.343 * *$ & $F=42.36^{* *}$ & & \\
\hline Thermic Arid & $0.134 *$ & $F=5.83^{*}$ & & \\
\hline Aspect & 0.028 & - & - & - \\
\hline Slope $\left(^{\circ}\right)$ & $0.148 * *$ & $F=7.12^{* *}$ & $20 ;[13.5,26.5]$ & $11.03 ;[7.6,14.4]$ \\
\hline Elevation (m) & $-0.153 * *$ & $F=7.67^{* *}$ & $1733.2 ;[1674.6,1791.7]$ & $1829.6 ;[1789.5,1869.68]$ \\
\hline Wind & $-0.130^{*}$ & $F=5.506^{*}$ & Dominant $=10 \% ;$ non dominant $=90 \%$ & $\begin{array}{l}\text { Dominant }=22.5 \% ; \text { non } \\
\text { dominant }=77.5 \%\end{array}$ \\
\hline
\end{tabular}

* denotes significance at $P<0.05 ; * *$ denotes significance at $P<0.01$ 
Feedback of bark beetle herbivory on tree condition may result in increasingly stressed trees that may either provide lowered defenses or greater nutritional quality (Reid and Robb 1999; Wichmann and Ravn 2001; Erbilgin and Raffa 2002; Sánchez-Martínez and Wagner 2002). Stress can be induced in trees by a diverse number of interacting conditions such as, water and nutrient deficiencies, increased tree and herbivory density, presence of other pest insects and diseases, topographic locations, and soil characteristics. During our study, the most extreme drought in recorded history occurred in northern Arizona, thus increasing the predisposition for I. confusus outbreaks. Under stressed host conditions I. confusus select the largest, oldest and slowest growing trees in the forest, providing the most food resources (Reid and Robb 1999). Studies on the Douglas fir beetle (Negron 1998) and mountain pine beetle (Amezaga and Rodríguez 1998) showed that niche-width and the probability of infestation are dependent on food resources. In an encounter rate model, it was shown that food items act as an attractant for Norway spruce bark beetle (Byers 1996; 2000). I. confusus in pinyon pine stands are also limited by food availability, as revealed by both correlation and logistic regression results. In I. confusus outbreak areas, food availability (volume of the cylinder around the trunk) was almost twice as high as in areas where I. confusus were absent. The contribution of food availability (basal area) to I. confusus outbreaks has been debated. Negron and Wilson (2003) showed a relationship between likelihood of outbreak and stand basal area, which was not supported by Floyd and others (2009). Our results, however, are consistent to those of Negron and Wilson (2003). Nonetheless further research should focus on clarifying this aspect of I. confusus ecology.

Previous studies in bark beetles associated with pinyon pine, ponderosa pine (Sánchez-Martínez and Wagner 2002), spruce (Wichmann and Ravn 2001), Douglas fir (Powers and others 1999) and red pine (Erbilgin and Raffa 2002) showed that bark beetle attacks are dependent on tree density, resulting in patches of infested and non-infested areas. Our results also support these findings by showing a positive association between the infestation of the nearest tree and the probability of an I. confusus attack (Tables 3, 4). Proximity to potential host trees may also increase the success of $I$. confusus to detect and recruit to a suitable tree and increase tree susceptibility, either because belowground impacts, such as herbivores and pests stress trees. Further, the presence of sub-canopy shrubs can also negatively affect the tree vigor during drought, which could increase the probability of infestation. For example, the growth and mycorrhizal associations of pinyon pines are negatively affected by the presence of sub-canopy shrubs, relative to those growing in the open or with their shrubs experimentally removed (McHugh and Gehring 2006). Our study supports this finding and further suggests that pinyon pines with sub-canopy vegetation were more likely to be infested with $I$. confusus than those without sub-canopy vegetation.

Bark beetle outbreaks have also been associated with interspecific interactions, such as predation (Reeve 1997; Gilbert and Grégoire 2003), and below- and aboveground herbivores of the same host (Erbilgin and Raffa 2002). Influence of other organisms, including herbivores and microorganisms, in bark beetle populations can be defined as those that predispose the tree to bark beetle attack [other herbivores; (Erbilgin and Raffa 2002)], and those that regulate bark beetle populations [predators; (Reeve 1997)]. Our results show that pinyons resistant to cone-boring moths are more susceptible to I. confusus attack. Three major factors could account for this pattern. First, because tree resistance to moths is genetically based (Mopper and others 1991; Gehring and others 1997; Brown and others 2001; Sthultz and others 2009), resistance to one herbivore may come at the cost of increased susceptibility to another. That is, no interactions of different herbivores need to be involved as resistance and susceptibility are innate and determine which trees will be attacked. Second, herbivores interact such that the presence of one makes the tree more or less susceptible to another herbivore through their impacts on the host plant defenses (Karban and Baldwin 1997). Third, moth herbivory alters the architecture of trees, turning them into shrubs, which shades out competing sub-canopy vegetation that can negatively affect a tree (McHugh and Gehring 2006).

At the landscape level, climate (Fredericksen and others 1995), topography, and wind stress have an effect on bark beetle infestation (Byers 2000; Wichmann and Ravn 2001). Slope influences bark beetle infestation by influencing soil depth, soil erosion, micro and macroclimate and root health, which may predispose trees for infestation by insects (Samman and Logan 2000; Gitlin and others 2006). Bark beetle infestations are more likely to occur in portions of the landscape that are potentially drier (lower elevations), if all other factors are similar (Powers and others 1999). Our results suggest that as slope increases, the probability of being attacked by I. confusus also increases. One possible explanation is that an increase in slope will increase water run-off, therefore creating a harsher environment for trees, which promote their susceptibility to I. confusus.

Soil characteristics determine vegetation physiological response and indirectly affect herbivores (Coulson 1979). Our results further suggest a negative association of frigid subhumid soil and bark beetle infestation (Table 3) as suggested by previous studies (Coulson 1979; Turner 1989). In the areas where frigid subhumid soil occurs (higher elevations and precipitation rates), trees may face reduced hydric stress conditions because of the higher 
Table 4 Variables driving I. confusus habitat selection in pinyon pine woodlands in Arizona

\begin{tabular}{|c|c|c|c|c|}
\hline Predictor variables & Coefficient & SE & Wald test & $P$-value \\
\hline Constant & -263.108 & 84.373 & 9.724 & 0.002 \\
\hline Infestation nearest tree & 3.466 & 1.141 & 9.219 & 0.002 \\
\hline Log food availability & 2.665 & 1.049 & 6.461 & 0.011 \\
\hline Moth phenotype & -2.665 & 0.895 & 8.866 & 0.003 \\
\hline Slope & 0.253 & 0.082 & 9.451 & 0.002 \\
\hline Elevation & 0.125 & 0.042 & 9.075 & 0.003 \\
\hline Wind & -2.347 & 1.036 & 5.135 & 0.023 \\
\hline Overall predictability (\%) & $96.9(95)$ & & & \\
\hline$R^{2}$ & 0.95 & & & \\
\hline AUC & 0.997 & & & \\
\hline
\end{tabular}

\begin{tabular}{llcc}
\hline & & \multicolumn{2}{l}{ Predicted values } \\
\cline { 3 - 4 } & & Presence & Absence \\
\hline Observed values & Presence & $114(39)$ & $6(4)$ \\
& Absence & $4(0)$ & $196(37)$
\end{tabular}

$B$ Constant value; $S E$ standard error; Wald Wald's test value; classification table with internal and external (in parenthesis) validation values and percentage of correct classifications and $R^{2}$ values

water storage capacity of the fine to gravelly soil particles. Improved hydrological conditions affect a tree's physiological condition and ability to produce chemical defenses such as resin (Cobb and others 1997). Long-lasting drought conditions have a variable effect on water storage and availability dependent on soil type, such that some areas represent more stressful environments for pinyon pines, which make them more susceptible to $I$. confusus outbreaks (Breshears and others 2005). However, it is important to notice that this association may be overthrown by the effect of slope and elevation and thus it is not significant in the final predictive model.

Other variables also potentially affect bark beetles host selection behavior. These include bark beetles attack density on host tree density and phloem thickness. In the current study we used $I$. confusus presence as a surrogate for density. However, some authors have demonstrated the role of density in host selection, indicating that at low beetle density the selected hosts are mainly stressed trees, whereas in high beetle density every tree is a potential host (Wallin and Raffa 2002). Despite not having collected the appropriate data to address the effect of I. confusus density on host selection, I. confusus were observed in both stressed and healthy trees, which may indicate a high I. confusus density. Once established in a host, bark beetles (in particular I. confusus) are phloem feeders. Our results suggest a very important role of food availability in predicting outbreaks, thus further developments of accurate estimates of phloem availability are warranted.
Modeling Outbreaks

Models provide testable hypotheses and predictions of biological patterns relevant to important problems (Burnham and Anderson 1998; Guisan and Zimmermann 2000). To our knowledge, few models have been applied to I. confusus outbreaks in the southwest, a region dominated by pinyon-juniper woodland that represents the 3rd largest vegetation type of the continental U.S.A. (West 1984). Thus, while numerous studies described above have shown patterns similar to those described herein, only a few have employed a modeling approach to detect presence of pest species (Negron 1998; Negron and Popp 2004). Negron and Popp (2004) developed classification and regression tree models for the mountain pine beetle, and suggested that models should help guide silvicultural treatments and restoration efforts by establishing stocking below levels that are associated with mountain pine beetle-caused mortality. Thus, our findings can also be used to define areas that are most likely to suffer from I. confusus outbreaks and to develop strategies that can minimize their impacts.

Testing the accuracy of model predictions is directly related to the estimation of their error rate. This procedure is optimized when one has two independent data sets (Guisan and Zimmermann 2000). In general linear models, $R^{2}$ values are most often used to test the goodness-of-fit between the model and the calibration data set. However, for nominal data, the probability of occurrence can be predicted and compared to real data when evaluating a model, using a contingency table-confusion matrix (Guisan and Zimmermann 2000), setting as a minimum acceptable model that correctly predicting over $70 \%$ of the data, which justifies the reliability of the model presented herein. Moreover, analyzing the area under the receiver operating curve also allows discerning between models. The greater the area is close to unity, the greater the model fit; our model had 0.99 of AUC demonstrating that the model is adequate to describe the system.

\section{Predicting I. confusus Disturbance in Pinyon Pine Woodlands}

Understanding and predicting disturbance patterns increases our knowledge on the mechanisms and processes that create and sustain biodiversity (Shea and others 2004). It is expected that in systems were multiple sequential disturbances occur, different outcomes of diversity are expressed (Shea and others 2004). This may be the case of the pinyon-juniper woodlands studied here, where sequential disturbance of drought followed by I. confusus outbreaks occurred. Following this prediction the patches affected by I. confusus will likely have a different diversity response 
than those only affected by drought, affecting future community integrity and function, even biodiversity creation processes. Furthermore, given the predicted increase in drought frequency in pinyon-juniper woodlands associated with climate change, it is important to predict the areas more likely to be disturbed by drought alone, and those by both drought and $I$. confusus. This will improve our understanding of the effects of disturbance legacy in observed biodiversity patterns and how to manage for these shifts.

\section{Management Implications}

Classifying bark beetles as pests and dead trees as losses depend on management goals (Samman and Logan 2000). Management goals for pinyon-juniper woodlands include increasing grassland habitat, grazing areas, and juniperdominated stands. Samman and Logan (2000) consider bark beetle outbreaks in the Coconino National Forest as beneficial as high pinyon pine mortality is thought to aid restoration of grasslands. Therefore, a no-action management strategy has been undertaken in those areas. However, in addition to I. confusus - induced tree mortality, severe drought result in rapid and extreme vegetation shifts at ecotones (Allen and Breshears 1998; Mueller and others 2005; Gitlin and others 2006; Breshears and others 2005). With a predicted climate change towards more frequent and long-lasting droughts, major shifts in the geographical distribution of plant communities, species composition and biodiversity are predicted (Parmesan and Yohe 2003; Root and others 2003). Arid lands may be particularly sensitive to climate changes (Risser 1995). As pinyon pines support a diverse community of about 1000 species from microbes to vertebrates (Whitham and others 2003; Swaty and others 2004), any change in the distribution and/or abundance of this dominant tree should have cascading affects on the rest of the community.

The use of systematic modeling approaches as that described herein serves to elucidate managers of the effectiveness of management actions and aid the re-evaluation of such management prescriptions. For I. confusus outbreaks in Arizona, alternative management options can be proposed. The first consists of developing a proactive policy of prevention of outbreaks by reducing stand susceptibility to I. confusus outbreaks. Our results suggest that denser stands, and the largest trees in specific geographical locations, will likely be those targeted by I. confusus. If a monitoring program is put in place to measure tree physiological condition, growth, production of resin (herbivore defenses), it will inform how the most susceptible trees are responding to the environmental conditions, and eventually determine a threshold that triggers their higher vulnerability to I. confusus. In addition, prescribed burns may be used to remove slash piles and understory, which may result in a decrease in I. confusus persistence in in-between outbreak periods. Targeted monitoring of I. confusus populations to estimate vital rates, population dynamics and source populations may allow delineating high outbreak risk areas, and detect population thresholds that dictate outbreaks. These monitoring activities will then allow for an effective management of I. confusus populations below outbreak thresholds. This is particularly important as I. confusus outbreaks can spread to other desired species, such as ponderosa pine (Pinus ponderosa), among others. Promoting these proactive management prescriptions, as elucidated by the model developed herein, further enhances the conservation of pinyon-juniper woodlands, and its associated biodiversity.

Acknowledgments This research was funded in part by NSF grants DEB-0236204 and DEB-0816675 and a fellowship to Maria J. Santos from the Luso-American Foundation for the Development. We thank R. Talbot Trotter III, Jesse Anderson, John Prather, J. J. Wynne, James Battin, Matt Bowker, Stacy Stumpf and Nashelly Meneses for their technical support, statistical analysis, and comments on this manuscript.

Open Access This article is distributed under the terms of the Creative Commons Attribution Noncommercial License which permits any noncommercial use, distribution, and reproduction in any medium, provided the original author(s) and source are credited.

\section{References}

Allen CD, Breshears DD (1998) Drought-induced shift of a forestwoodland ecotone: rapid landscape response to climate variation. Proceedings of the Natural Academy of Sciences 95:1483914842

Amezaga I, Rodríguez MA (1998) Resource partitioning of four sympatric bark beetles depending on swarming dates and tree species. Forest Ecology and Management 109:127-135

Breshears DD, Cobb NS, Rich PM, Price KP, Allen CD, Balice RG, Romme WH, Kastens JH, Floyd ML, Belnap J, Anderson JJ, Myers OB, Meyer CW (2005) Regional vegetation die-off in response to global-change-type drought. Proceedings of the Natural Academy of Sciences 102:15144-15148

Brown JH, Whitham TG, Morgan ESK, Gehring CA (2001) Complex species interactions and the dynamics of ecological systems: long-term experiments. Science 293:643-650

Burnham KP, Anderson DR (1998) Model selection and inference. Springer, New York

Byers JA (1996) An encounter rate model of bark beetle populations searching at random for susceptible host trees. Ecological Modelling 91:57-66

Byers JA (2000) Wind-aided dispersal of simulated bark beetles flying through forests. Ecological Modelling 125:231-243

Campbell JW, Hanula JL, Outcalt KW (2008) Effects of prescribed fire and other plant community restoration treatments on tree mortality, bark beetles, and other saproxylic Coleoptera of longleaf pine Pinus pallustris Mill., on the Coastal Plain of Alabama. Forest Ecology and Management 254:134-144

Cobb NS, Whitham TG (1993) Herbivore deme formation on individual trees: a test case. Oecologia 94:496-502 
Cobb NS, Mopper S, Gehring CA, Caouette M, Christensen KM, Whitham TG (1997) Increased moth herbivory associated with environmental stress of pinyon pine at local and regional levels. Oecologia 109:389-397

Coulson RN (1979) Population dynamics of bark beetles. Annual Review of Entomology 24:417-447

Erbilgin N, Raffa KF (2002) Spatial analysis of forest gaps resulting from bark beetle colonization of red pines experiencing belowground herbivory and infection. Forest Ecology and Management 177:145-153

Floyd ML, Clifford M, Cobb NS, Hanna D, Delph R, Ford P, Turner D (2009) Relationship of stand characteristics to droughtinduced mortality in three Southwestern piñon-juniper woodlands. Ecological Applications 19:1223-1230

Fredericksen TS, Hedden RL, Williams SA (1995) Susceptibility of loblolly pine to bark beetle attack following simulated wind stress. Forest Ecology and Management 76:95-107

Gehring CA, Cobb NS, Whitham TG (1997) Three-way interactions among ectomycorrhizal mutualists scale insects and resistant and susceptible pinyon pines. The American Naturalist 149:824-841

Gilbert M, Grégoire JC (2003) Site condition and predation influence a bark beetle's success: a spatially realistic approach. Agricultural and Forestry Entomology 5:87-96

Gitlin A, Stultz CM, Bowker MA, Stumpf S, Ecton K, Kennedy K, Munoz A, Bailey JK, Whitham TG (2006) Mortality gradients within and among dominant plant populations as barometers of ecosystem change during extreme drought. Conservation Biology $20: 1477-1486$

Guisan A, Zimmermann NE (2000) Predictive habitat distribution models in ecology. Ecological Modelling 135:147-186

Hanley JA, McNeil BJ (1982) The meaning and use of the area under a Receiver Operating Characteristic (ROC) Curve. Radiology 143:29-36

Hanula JL, Franzreb K (1998) Source, distribution and abundance of macroarthropods on the bark of longleaf pine: potential prey if the red-cockaded woodpecker. Forest Ecology and Management 102:89-102

Hendricks DM (1985). Arizona soils. In: Co Agriculture (ed). University of Arizona, Tucson

Hosmer JR, Lemeshow DW (2000) Applied logistic regression. Wiley, New York

Jackson JF, Adams DC, Jackson UB (1999) Allometry of constitutive defense: a model and a comparative test with tree bark and fire regime. The American Naturalist 153:614-632

Karban R, Baldwin IT (1997) Induced responses to herbivory. University of Chicago Press, Chicago

Klink K (1999) Climatological mean and interannual variance of United States surface wind speed, direction and velocity. International Journal of Climatology 19:471-488

Logan JA, White P, Bentz BJ, Powell JA (1998) Model analysis of spatial patterns in mountain pine beetle outbreaks. Theoretical Population Biology 53:236-255

McHugh TA, Gehring CA (2006) Below-ground interactions with arbuscular mycorrhizal shrubs decrease the performance of pinyon pine and the abundance of its ectomycorrhizas. New Phytologist 171:171-178

Mopper S, Mitton J, Whitham TG, Cobb N, Christensen KM (1991) Genetic differentiation and heterozygosity in pinyon pine associated with herbivory and environmental stress. Evolution 45:989-999

Moran PAP (1950) A test for the serial independence of residuals. Biometrika 37:178-181

Mueller RC, Scudder CM, Porter ME, Trotter RT, Gehring CA, Whitham TG (2005) Differential tree mortality in response to severe drought: evidence for long-term vegetation shifts. Journal of Ecology 93:1085-1093
Negron JF (1998) Probability of infestation and extent of mortality associated with the Douglas-fir beetle in the Colorado Front Range. Forest Ecology and Management 107:71-85

Negron JF, Popp JB (2004) Probability of ponderosa pine infestation by mountain pine beetle in the Colorado Front Range. Forest Ecology and Management: 17-27

Negron JF, Wilson JW (2003) Attributes associated with probability of infestation by the pinon Ips confusus (Coleoptera: Scolytidae), in pinyon pine, Pinus edulis. Western North American Naturalist 63:440-451

Ogle K, Whitham TG, Cobb NS (2000) Tree-ring variation in pinyon predicts likelihood of death following severe drought. Ecology 81:3237-3243

Parmesan C, Yohe G (2003) A globally coherent fingerprint of climate change impacts on natural systems. Nature 421:37-42

Powers JS, Sollins P, Harmon ME, Jones JA (1999) Plant-pest interactions on time and space: a Douglas-fir bark beetle outbreak as a case study. Landscape Ecology 14:105-120

Reeve JD (1997) Predation and bark beetle dynamics. Oecologia 112:48-54

Reid ML, Robb T (1999) Death of vigorous trees benefits bark beetles. Oecologia 120:555-562

Risser PG (1995) The status of the science of examining ecotones. Bioscience 45:318-325

Root TL, Price JT, Hall KR, Schneider SH, Rosenzweig C, Pounds JA (2003) Fingerprints of global warming on wild animals and plants. Nature 421:57-60

Samman S, Logan J (2000) Assessment and response to bark beetle outbreaks in the Rocky Mountain area. United States Department of Agriculture, Ogden

Sánchez-Martínez G, Wagner MR (2002) Bark beetle community structure under four ponderosa pine forest stand conditions in northern Arizona. Forest Ecology and Management 170:145-160

Shea K, Roxburgh SH, Rauschert ESJ (2004) Moving from pattern to process: coexistence mechanisms under intermediate disturbance regimes. Ecology Letters 7:491-508

Sthultz CM, Gehring CA, Whitham TG (2009) Deadly combination of genes and drought: Increased mortality of herbivore-resistant trees in a foundation species. Global Change Biology 15:1949-1961

Swaty RL, Deckert RJ, Whitham TG, Gehring CA (2004) Ectomycorrhizal abundance and community composition shifts with drought: predictions from tree rings. Ecology 85:1072-1084

Trapp S, Croteau R (2001) Defensive resin biosynthesis in conifers. Annual Review of Plant Physiology 52:689-724

Trotter-III RT, Cobb NS, Whitham TG (2002) Herbivory, plant resistance, and climate in the tree ring record: interactions distort climatic reconstructions. Proceedings of the Natural Academy of Sciences 99:10197-10202

Turner MG (1989) Landscape ecology: the effect of pattern on process. Annual Review of Ecology and Systematics 20:171-197

USDA (2003) Pine Bark Beetle Situation in Arizona Southwestern Region. http://www.swstrategy.org/rec/REC_Meeting_Minutes/ Jun_03/Apdx_B-1_Bark_Beetle_Arizona_April_2003.pdf

Wallin KF, Raffa KF (2002) Density-mediated responses of bark beetles to host allelochemicals: a link between individual behaviour and population dynamics. Ecological Entomology 27: 484-492

Weslien J, Schroeder LM (1999) Population levels of bark beetles and associated insects in managed and unmanaged spruce stands. Forest Ecology and Management 115:267-275

West NE (1984) Successional patterns and productivity potentials of pinyon-juniper ecosystems. Developing strategies for range management: a report. Westview Press, Boulder, pp 1301-1332

Whitham TG, Mopper S (1985) Chronic herbivory: impacts on architecture and sex expression of pinyon pine. Science 228: $1089-1090$ 
Whitham TG, Young WP, Martinsen GD, Gehring CA, Schweitzer JA, Shuster SM, Wimp GM, Fischer DG, Bailey JK, Lindroth RL, Woolbright S, Kuske CR (2003) Community and ecosystem genetics: a consequence of the extended phenotype. Ecology 84: 559-573

Wichmann L, Ravn HP (2001) The spread of Ips typographus (L.) (Coleoptera, Scolytidae) attacks following heavy windthrow in
Denmark, analysed using GIS. Forest Ecology and Management 148:31-39

Zar JH (1999) Biostatistical analysis. Prentice-Hall, Upper Saddle River, NJ 